\title{
A Comparative Study on the Spatial Fractal Comparison of the Tourism City System of Urban Agglomerations in the Central Region
}

\author{
LIU Chun ${ }^{1,2, a, ~ * ~}$
}

1. Wuhan Technology and Business University, Department of Management, Wuhan 430065

2. Hubei Business Service Development Research Center

${ }^{\mathrm{a} L c 576 @ 126 . c o m ~}$

\begin{abstract}
With the comprehensive economic strength of urban agglomerations in the central region, the tourism economic ties more closely within the region, a higher demand on the regional tourism spatial structure. This paper comparatively analyses tourism spatial structure of 6 urban agglomerations in the central region, by the use of the fractal method, achieves 4 conclusions: (1) 6 urban agglomerations in the central region has the spatial fractal character, and Multifractal obviously, four subsystems; (2) Crow fractal dimension of Taiyuan urban agglomeration is the highest, Poyang Lake urban agglomeration the lowest, the whole spatial correlation is higher than that of the individual in city groups of the central region; (3) There is an axis characteristic of spatial structure in Wuhan urban agglomeration, the city cluster along Anhui-Yangtse River and the Taiyuan urban agglomeration; (4) Traffic network of Taiyuan urban agglomeration is the best in urban agglomerations of the central region, that of Taiyuan urban agglomeration is the worst, the whole traffic network is better than that of the individual in urban agglomerations of the central region.
\end{abstract}

Key words: Fractal; Urban agglomeration; Tourism Spatial Structure; the Central Region

\section{Introduction}

Urban agglomeration is an advanced form of urban spatial organization in the process of urbanization. It plays an important role, and plays a huge role in traction and promotion in the development of regional economy and society ${ }^{[1]}$. Urban agglomeration is the symbol of urbanization to a certain level, and the spatial distribution of regional economic integration. The spatial structure of tourism is formed by the spatial interaction of many elements of tourism activities, which reflects the spatial relationship of tourism activities, which is the projection of tourism activities in the geographical space, which is the result of the accumulation of tourism activity and location choice in the long-term tourism development ${ }^{[2]}$. It can promote the sustainable development of the urban agglomeration tourism to correctly understand the current situation of the tourism spatial structure of the urban agglomeration and master the evolution law of the tourism spatial structure of the urban agglomeration. It is of great practical significance to study the spatial structure and formation mechanism of urban agglomeration tourism.

In April 2006, the State Council of the PRC "Some issues on Promoting the Rise of the Central Region”, enhance the radiation function of central city, promote the development of urban agglomerations and counties, cultivate tourism industry in the central region into an important industry. In September 2009, the National Development and Reform Commission of the PRC "Promote the Rise of the Central Region Planning", focus on optimizing the spatial layout of the central region, cultivate urban agglomeration growth pole, further optimize and integrate all kinds of tourism resources, strive to build a number of tourism brands with the characteristics of the central region, jointly promote the development of barrier free tourism, establish and improve the mechanism of regional tourism cooperation. In August 2012, the State Council of the PRC promulgated the "Guidelines on Vigorously Implement the Strategy of Spurring the Rise of the Central Region", referred to urban agglomerations play a leading role of the rise of the central region, implementation 
of the central city driven strategy, scientific planning function positioning and industrial layout of each city in urban agglomerations, further strengthening the flow of production factors and function relation, accomplishing coordinated development, encouraging key fields of cooperation in infrastructure, information platform, tourism development, ecological protection and other in the central six provinces.

The central region is the population and urban intensive areas in China, has initially formed the development pattern of six urban agglomerations including Wuhan urban agglomeration, Central Henan urban agglomeration, Changzhutan urban agglomeration, the city cluster along Anhui-Yangtse River, Poyang Lake urban agglomeration and Taiyuan urban agglomeration. The central region has unique conditions for the development of tourism, The rise of tourism in the central region is considered to be the leading industry in the rise of the central region, the rise of the central region needs to rely on the support of urban agglomerations. In this paper, the optimization of urban agglomerations tourism spatial structure in the central area, to play the advantages of tourism resources in urban agglomerations of the central area, to build a reasonable tourism spatial structure, to achieve urban agglomerations interaction, to promote the sustainable development of urban agglomerations tourism, to provide constructive suggestions to the rise of the central region.

\section{A review of the research on tourism spatial structure of Urban Agglomeration}

Scholars began to study the spatial structure of tourism in 1960s. American scholar Gunn (1972) and Australian scholar Leiper (1995) have proposed the concept of tourism spatial system ${ }^{[3-4]}$. Pearce (1999) studies the distribution and function of tourism space in order to achieve the maximization of urban tourism space ${ }^{[5]}$. WENG Jin (2007) establishes a tourism spatial competition model of economic scale, travel cost, preference and tourism product differentiation ${ }^{[6]}$. Marrocu Emanuela, Paci Raffaele (2011) study on the spatial behavior of tourist flows in EU member states ${ }^{[7]}$.

Chinese scholars can review the research methods of the tourism spatial structure of Urban Agglomeration: LIN Lan (2011) ${ }^{[8]}$, JIANG Ming-ping (2012) ${ }^{[9],}$ LIU Da-jun (2013) ${ }^{[10]}$ and DUAN Bing (2015) ${ }^{[11]}$ applied the fractal theory to study the spatial structure and the spatial difference of tourism system in regional urban, put forward the optimization strategy of tourism spatial system. CHEN Hao (2008) ${ }^{[12]}$, WANG Lang (2010) ${ }^{[13]}$, ZHANG Hong (2011) ${ }^{[14]}$, CHEN Hao (2011) ${ }^{[15]}$, SHEN Jing-hong (2012) ${ }^{[16]}$, CAO Fang-dong (2012) ${ }^{[17]}$, SUN Dong-qi (2013) ${ }^{[18]}$ constructs the linkage intensity, connectivity and accessibility model to analyze the evolution, pattern and optimization of tourism spatial structure of urban agglomeration. FANG Ye-lin (2013) ${ }^{[19]}$, YU Hu (2014) ${ }^{[20]}$ and LIU Chun $(2015)^{[21]}$ make a quantitative study on the tourism network structure of the urban agglomerations by the method of social network analysis, reveal the internal mechanism of the regional tourism economic development difference, and construct the model of the tourism spatial network structure. In addition, BIAN Xian-hong (2007) ${ }^{[22]}$, XIE Shou-hong (2008) ${ }^{[23]}$, LI Hong-bo (2011) ${ }^{[24]}$, ZHAO Rui-xia (2011) ${ }^{[25]}$, ZHU Fu-biao (2012) ${ }^{[26]}$, FANG Fa-lin (2013) ${ }^{[27]}$ make qualitative and quantitative research on the tourism spatial structure of urban agglomeration by the theory of point-axis, principal component analysis, Herfindahl-Hirschman index, rank-size rule and Theil index.

In general, the research on the spatial structure of regional tourism in China is the developing 
period. The research methods of tourism space are limited to common mathematical statistics methods. The research on tourism spatial structure of urban agglomeration needs to be deepened. This paper applies the fractal theory to study tourism spatial structure of urban agglomeration, make a comparative study on tourism spatial structure of the 6 urban agglomerations in the central region, reveal the characteristics of the tourism spatial structure of the whole and individual in 6 urban agglomerations. Finally put forward suggestions on tourism spatial layout optimization of the urban agglomerations in the central region.

3 Fractal research method of urban system spatial structure of urban agglomerations in the central region

\subsection{Aggregation dimension measurement}

Assume that the distribution of regional excellent tourism city around the central tourism city in accordance with some self-similar rules performs condensed state, and the fractal body of regional excellent tourism city is uniformly distributed, then we can determine the relationship between the circle of $r$ radius in number of excellent tourism cities and the corresponding radius by means of geometric measure method, i.e. there:

$$
N(\mathrm{r}) \propto r^{D f}
$$

(1) formula: $D f$ for fractal dimension. Taking into account that the unit value of the radius $r$ affects the value of the spatial fractal dimension of excellent tourism city, it can be transformed into an average radius ${ }^{[28]}$, average radius formula for

$$
R_{s}=\sqrt{\sum_{i=1}^{s} \frac{r_{i}^{2}}{S}}
$$

Then there will be fractal dimension:

$$
R_{s} \propto S^{\frac{1}{D}}
$$

Formula (2) and (3) $: R_{s}$ is the average radius between excellent tourism cities; $r_{i}$ is euclidean distance between excellent tourism city $i$ and the central tourism city; $S$ is the number of excellent tourism cities; $D$ is the spatial fractal dimension of excellent tourism cities, $D$ reflects the compact characteristics of spatial structure of regional excellent

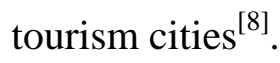

Generally speaking, when the agglomeration dimension $D$ is less than 2 , the spatial distribution density of excellent tourism cities gradually decline from the central tourism city to periphery, known as aggregated distribution. When the agglomeration dimension $D$ is equal to 2, the spatial distribution of excellent tourism cities uniformly varying from the central city to periphery. when the agglomeration dimension greater than 2 , the spatial distribution density of excellent tourism cities gradually increasing from the central tourism city to periphery, this is an abnormal situation.

\section{2 correlation dimension measurement}

It is assumed that there are $N$ excellent tourism cities in the region, and the spatial 
correlation functions between these excellent tourism cities can be expressed as $^{[29]}$ :

$$
C(r)=\frac{1}{N^{2}} \sum_{i}^{N} \sum_{j}^{N} H\left(r-d_{i j}\right) \quad(i \neq j)
$$

(4) formula: $r$ is yardstick; $d_{i j}$ is the crow distance ( or cow distance ) between crows for excellent tourism city $i$ and excellent tourism city $j$; $H\left(r-d_{i j}\right)$ is Heaviside function, as follows:

$$
H\left(r-d_{i j}\right)=\left\{\begin{array}{ll}
1, & \left(d_{i j} \leq r\right) \\
0, & \left(d_{i j}>r\right)
\end{array} \quad(i \neq j)\right.
$$

If the spatial distribution of excellent tourism cities is fractal, it should have scaling invariability, expression as follows:

$$
C(\mathrm{r}) \propto r^{D}
$$

(6) formula: $D$ is fractal dimension, called spatial correlation dimension, which reflects the relevance and accessibility of traffic network between excellent tourism cities.

In general, the correlation dimension $D$ vary range from 1 to 2 . When the correlation dimension $D$ is close to 1 , the excellent tourism cities distribution have a tendency to concentrate to a geographical line, such as railway, highway, mountains, rivers, coastal etc. When the smaller the correlation dimension $D$, the more concentrated the excellent tourism cities spatial distribution, the stronger the interaction between the excellent tourism cities. On the contrary, when the larger the correlation dimension $D$, the uniformer the excellent tourism cities spatial distribution, the weaker the interaction between the excellent tourism cities $^{[20]}$.

The application of spatial correlation dimension indicates the relevance between tourism cities by network accessibility degree. The definition of network accessibility degree is as follows:

$$
\rho=\frac{D^{\prime}}{D}
$$

(7) formula: $D^{\prime}$ is cow dimension, namely, the fractal dimension obtained from $d_{i j}$ instead of the traffic distance. $D$ is crow dimension, namely, the fractal dimension obtained from $d_{i j}$ instead of the euclidean distance. $\rho$ is the ratio of cow dimension to crow dimension, which reflects network accessibility degree between the excellent tourism cities. The more close to $1 \rho$ value, the better the traffic network accessibility between tourism cities, the higher the correlation degree between tourism cities ${ }^{[20]}$. When $\rho$ is less than 0.5 , the traffic network connectivity between the excellent tourism cities is poor. When $\rho$ is less than 1 , and greater than 0.5 , the traffic network connectivity between the excellent tourism cities is good. When $\rho$ is equal to 1 , the traffic network connectivity between the excellent tourism cities reach the limit of the best ${ }^{[31]}$. 
4 An empirical study on the spatial structure fractal of tourism cities in the urban agglomerations in the central region

4.1 The general situation of urban agglomerations of the central region

The distribution of the population and urban in the central region is more dense than other areas of China. In this paper, the research object of urban agglomeration in the central region covers 48 cities of six urban agglomerations including Wuhan urban agglomeration, Central Henan urban agglomeration, Changzhutan urban agglomeration, the city cluster along Anhui-Yangtse River, Poyang Lake urban agglomeration and Taiyuan urban agglomeration, land area of $474567 \mathrm{~km}{ }^{2}$. By 2015 year, residents population by urban agglomeration in central region 194.47 million people, the urbanization rate level $56.11 \%$, GDP of 9.817093 trillion yuan, area rich in tourism resources, the Total Tourism Earnings by urban agglomeration in the central region 2.38324 trillion yuan, Number of Visitors from home and abroad 1.879 billion tourists, including 10.2247 million Number of Oversea Visitor Arrivals, Foreign Exchange Earnings from International Tourism of $\$ 4.68$ billion, Urban agglomerations tourism has a pivotal position in economic and social development in the central region.

\subsection{Sources of date}

In this paper, the original data is derived from the Hubei statistical yearbook (2016), the Hunan statistical yearbook (2016), the Jiangxi statistical yearbook (2016), the Anhui statistical yearbook (2016), the Henan statistical yearbook (2016), the Shanxi statistical yearbook (2016). The Traffic distances (unit: $\mathrm{km}$ ) between the both urban in the urban agglomerations are collated according to the shortest highway distance between the both urban in Baidu maps. The Euclidean distances (unit: $\mathrm{km}$ ) between the both urban are obtained through the calculation of the latitude and longitude of urban.

4.3 The fractal dimension measurement of spatial structure of six urban agglomerations in the central region

Taking Wuhan as the measure center of six urban agglomerations in the central region, calculate the gravity distance $\left(r_{\mathrm{i}}\right)$ between the measure center city Wuhan and each city in six urban agglomerations, and converted the gravity distance to the average radius of $R$ s ( Table 1 ), then double logarithmic plots ( Figure 1 ) is drawn by the values of the dot ( $S$, Rs ). By means of least square method, this paper can measure the aggregation dimension $D$ of the spatial structure of the urban agglomerations in the central region. 
Tab.1 The fractal dimension of the spatial structure of the urban agglomerations in the central region based on Wuhan as the center of measurement

\begin{tabular}{lccclccc}
\hline \multicolumn{1}{c}{ City } & $\boldsymbol{S}$ & $\boldsymbol{r}_{\mathbf{i}}$ & $\boldsymbol{R s}$ & City & $\boldsymbol{S}$ & $\boldsymbol{r}_{\mathbf{i}}$ & $\boldsymbol{R s}$ \\
\hline Wuhan & 1 & 0 & 0 & Fuzhou & 25 & 337 & 240.87 \\
Huanggan & 2 & 35 & 24.75 & Xiangtan & 26 & 353 & 246.13 \\
Ezhou & 3 & 36 & 28.99 & Pingdings & 27 & 357 & 251.11 \\
Xiaogan & 4 & 65 & 41.07 & Ji'an & 28 & 367 & 256.17 \\
Huangshi & 5 & 83 & 52.22 & Yingtan & 29 & 371 & 260.97 \\
Xiantao & 6 & 88 & 59.69 & Shangrao & 30 & 391 & 266.33 \\
Xianning & 7 & 91 & 65.09 & Wuhu & 31 & 398 & 271.57 \\
Tianmen & 8 & 103 & 70.95 & Loudi & 32 & 410 & 276.95 \\
Qianjiang & 9 & 158 & 85.14 & Xuanchen & 33 & 410 & 281.91 \\
Yueyang & 10 & 165 & 96.16 & Ma'anshan & 34 & 411 & 286.53 \\
Jiujiang & 11 & 170 & 105.04 & Xuchang & 35 & 412 & 290.87 \\
Nanchang & 12 & 255 & 124.63 & Chuzhou & 36 & 432 & 295.70 \\
Anqing & 13 & 274 & 141.82 & Kaifeng & 37 & 459 & 301.28 \\
Changsha & 14 & 292 & 157.37 & Hengyang & 38 & 460 & 306.51 \\
Yiyang & 15 & 293 & 169.82 & Zhengzho & 39 & 463 & 311.51 \\
Changde & 16 & 297 & 180.41 & Luoyang & 40 & 486 & 317.04 \\
Chizhou & 17 & 299 & 189.45 & Xinxiang & 41 & 541 & 324.35 \\
Hefei & 18 & 315 & 198.52 & Jiaozuo & 42 & 542 & 331.20 \\
Jingdezhe & 19 & 315 & 206.30 & Jiyuan & 43 & 549 & 337.86 \\
Tongling & 20 & 318 & 213.28 & Yangquan & 44 & 801 & 355.16 \\
Yichun & 21 & 321 & 219.58 & Taiyuan & 45 & 818 & 371.76 \\
Xinyu & 22 & 322 & 225.23 & Jinzhong & 46 & 826 & 387.34 \\
Luohe & 23 & 332 & 230.90 & Lvliang & 47 & 846 & 402.58 \\
Zhuzhou & 24 & 333 & 236.04 & Xinzhou & 48 & 893 & 418.70 \\
\hline
\end{tabular}

As shown in figure 1, there is obvious four non-scaling ranges of the spatial structure of the urban agglomerations in the central region, indicates that the spatial structure of the urban agglomerations in the central region has a fractal characteristic, and obvious multifractal characteristics with four subsystems. The first non-scaling range, the corresponding $R s$ is $24.75-70.95 \mathrm{~km}$, the value spatial random aggregation dimension is 0.818 . The second non-scaling range, the corresponding $R s$ is $70.95-169.82 \mathrm{~km}$, the value spatial random aggregation dimension is 1.404. The third non-scaling range, the corresponding $R s$ is $169.82-337.86 \mathrm{~km}$, the value spatial random aggregation dimension is 0.603 . The fourth non-scaling range, the corresponding $R s$ is $337.86-418.70 \mathrm{~km}$, the value spatial random aggregation dimension is 1.958 .

This shows that in the range of the different space, the development difference of the spatial structure between tourism cities in urban agglomerations of the central region is relatively large, tourism cities have obvious agglomeration characteristics in different spatial scales, and the circle-and-layer spatial structure of tourism cities is more obvious, spatial distribution of tourism cities in the fourth non-scaling range is the most compact, spatial distributions of tourism cities in the second and first non-scaling range are the next, spatial distributions of tourism cities in the third non-scaling range is relatively loose. 


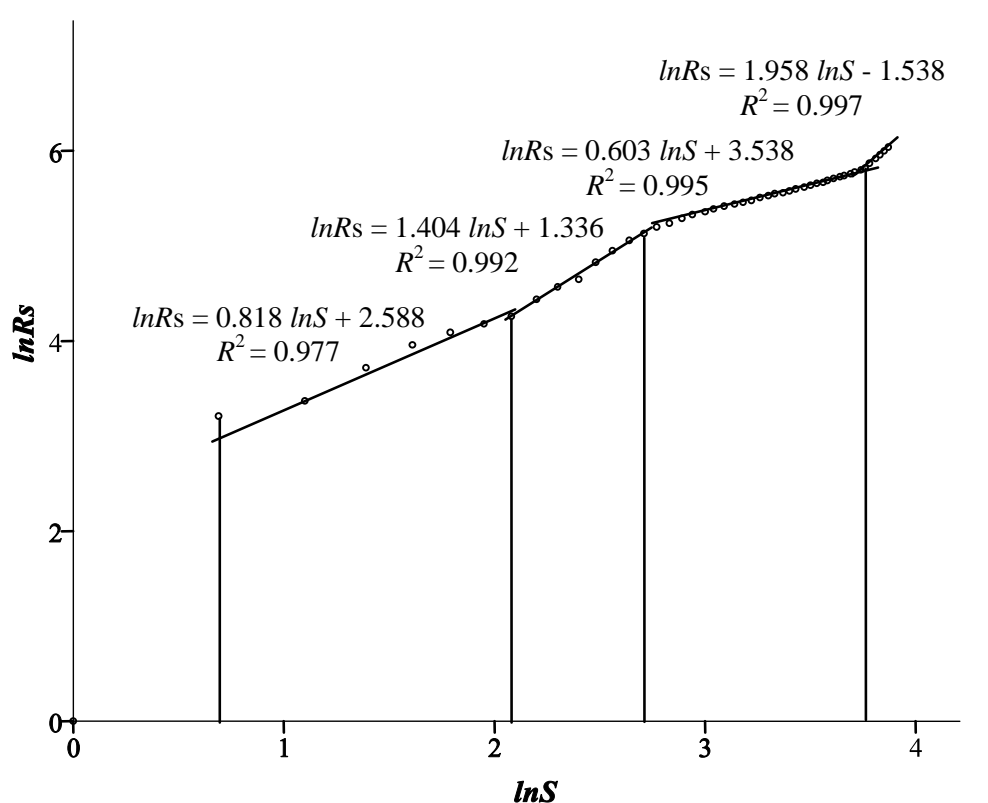

Fig.1 Double logarithmic plots of spatial structure dimension of urban agglomerations

4.4 Calculation of correlation dimension of spatial structure of tourism cities in the urban agglomerations of the central region

According to the distance between tourism cities of six urban agglomerations in the central region, this paper determines yardstick $\Delta r=15 \mathrm{~km}$, then the distance points $C$ $(r)$ between tourism cities of six urban agglomerations within the distance $r$ of both in urban agglomerations will change with the change of $r$. In this way, we can get the dot matrix $[r, C(r)]$ according to the distance of the crow and the cow （table 2, table3）. By the use of SPSS software, the dot matrix $[r, C(r)]$ is converted into the corresponding double logarithmic matrix. The crow correlation dimension $D$ and cow correlation dimension $D^{\prime}$ were calculated for six urban agglomerations by linear regression model, and the same way to the crow correlation dimension $D$ and cow correlation dimension $D^{\prime}$ for the whole urban agglomeration of the central region (figure 2, figure 3 ), and further calculate the ratio of cow dimension to crow dimension of urban system spatial structure in three urban agglomerations ( Table 4 ). 
Table $2 d_{i j}$ for traffic distance, the yardstick $r$ and the number of distance selected

\begin{tabular}{|c|c|c|c|c|c|c|c|c|c|c|c|c|c|c|c|c|c|c|c|c|c|c|c|c|c|c|c|c|c|}
\hline 序号 & & 1 & 2 & 3 & 4 & 5 & 6 & 7 & 8 & 9 & 10 & 11 & 12 & 13 & 14 & 15 & 16 & 17 & 18 & 19 & 20 & 21 & 22 & 23 & 24 & 25 & 26 & 27 & 28 \\
\hline & $r$ & 15 & 30 & 45 & 60 & 75 & 90 & 105 & 120 & 135 & 150 & 165 & 180 & 195 & 210 & 225 & 240 & 255 & 270 & 285 & 300 & 315 & 330 & 345 & 360 & 375 & 390 & 405 & 420 \\
\hline $\begin{array}{l}\text { Wuhan urban } \\
\text { agglomeration }\end{array}$ & $N(r)$ & 0 & 2 & 4 & 10 & 12 & 18 & 24 & 26 & 32 & 36 & 46 & 52 & 56 & 60 & 62 & 68 & 72 & - & - & - & - & - & - & - & - & - & - & - \\
\hline $\begin{array}{l}\text { Changzhutan } \\
\text { urban } \\
\text { agglomeration }\end{array}$ & $N(r)$ & 0 & 0 & 2 & 2 & 6 & 8 & 10 & 14 & 14 & 26 & 30 & 34 & 36 & 44 & 44 & 46 & 48 & 50 & 50 & 52 & 52 & 54 & 56 & - & - & - & - & - \\
\hline $\begin{array}{l}\text { Poyang Lake } \\
\text { urban } \\
\text { agglomeration }\end{array}$ & $N(r)$ & 0 & 0 & 0 & 0 & 2 & 2 & 4 & 6 & 12 & 14 & 20 & 22 & 24 & 28 & 38 & 38 & 42 & 46 & 48 & 50 & 52 & 54 & 56 & 60 & 64 & 64 & 68 & 72 \\
\hline $\begin{array}{l}\text { the city cluster } \\
\text { along } \\
\text { Anhui-Yangtse } \\
\text { River }\end{array}$ & $N(r)$ & 0 & 0 & 0 & 4 & 8 & 8 & 16 & 18 & 22 & 28 & 32 & 34 & 40 & 48 & 48 & 52 & 52 & 52 & 54 & 56 & - & - & - & - & - & - & - & - \\
\hline $\begin{array}{l}\text { Central Henan } \\
\text { urban } \\
\text { agglomeration }\end{array}$ & $N(r)$ & 0 & 0 & 0 & 0 & 6 & 10 & 18 & 22 & 28 & 36 & 42 & 44 & 52 & 56 & 62 & 70 & 70 & 70 & 70 & 72 & - & - & - & - & - & - & - & - \\
\hline $\begin{array}{l}\text { Taiyuan urban } \\
\text { agglomeration }\end{array}$ & $N(r)$ & 0 & 0 & 2 & 2 & 2 & 4 & 6 & 10 & 10 & 10 & 10 & 10 & 14 & 14 & 16 & 16 & 16 & 18 & 20 & - & - & - & - & - & - & - & - & - \\
\hline
\end{tabular}

Table3 $d_{i j}$ for euclidean distance, the yardstick $r$ and the number of distance selected

\begin{tabular}{|c|c|c|c|c|c|c|c|c|c|c|c|c|c|c|c|c|c|c|c|c|c|c|c|c|c|}
\hline 序号 & & 1 & 2 & 3 & 4 & 5 & 6 & 7 & 8 & 9 & 10 & 11 & 12 & 13 & 14 & 15 & 16 & 17 & 18 & 19 & 20 & 21 & 22 & 23 & 24 \\
\hline & $r$ & 15 & 30 & 45 & 60 & 75 & 90 & 105 & 120 & 135 & 150 & 165 & 180 & 195 & 210 & 225 & 240 & 255 & 270 & 285 & 300 & 315 & 330 & 345 & 360 \\
\hline $\begin{array}{l}\text { Wuhan urban } \\
\text { agglomeration }\end{array}$ & $N(r)$ & 2 & 4 & 8 & 16 & 22 & 30 & 40 & 46 & 50 & 56 & 60 & 64 & 70 & 70 & 70 & 70 & 72 & - & - & - & - & - & - & - \\
\hline $\begin{array}{l}\text { Changzhutan } \\
\text { urban } \\
\text { agglomeration }\end{array}$ & $N(r)$ & 0 & 0 & 0 & 4 & 6 & 8 & 14 & 16 & 30 & 34 & 36 & 40 & 44 & 48 & 48 & 50 & 52 & 52 & 52 & 54 & 56 & - & - & - \\
\hline $\begin{array}{l}\text { Poyang Lake } \\
\text { urban } \\
\text { agglomeration } \\
\text { the city cluster }\end{array}$ & $N(r)$ & 0 & 0 & 2 & 6 & 10 & 14 & 14 & 18 & 20 & 24 & 28 & 36 & 38 & 44 & 48 & 50 & 54 & 56 & 58 & 60 & 62 & 64 & 70 & 72 \\
\hline $\begin{array}{c}\text { along } \\
\text { Anhui-Yangtse } \\
\text { River }\end{array}$ & $N(r)$ & 0 & 6 & 6 & 8 & 10 & 12 & 18 & 30 & 38 & 42 & 46 & 48 & 52 & 52 & 54 & 56 & - & - & - & - & - & - & - & - \\
\hline $\begin{array}{l}\text { Central Henan } \\
\text { urban } \\
\text { agglomeration }\end{array}$ & $N(r)$ & 0 & 0 & 2 & 4 & 12 & 22 & 26 & 34 & 44 & 52 & 54 & 56 & 62 & 66 & 70 & 70 & 72 & - & - & - & - & - & - & - \\
\hline $\begin{array}{l}\text { Taiyuan urban } \\
\text { agglomeration }\end{array}$ & $N(r)$ & 0 & 0 & 2 & 4 & 6 & 10 & 10 & 14 & 14 & 16 & 16 & 16 & 20 & - & - & - & - & - & - & - & - & - & - & - \\
\hline
\end{tabular}




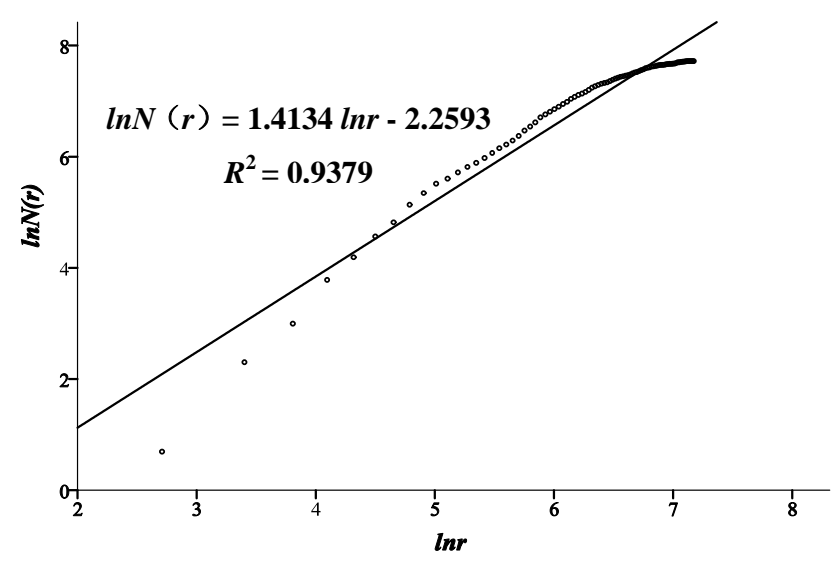

Fig. 2 Double logarithmic plot of correlation dimension of crow distance

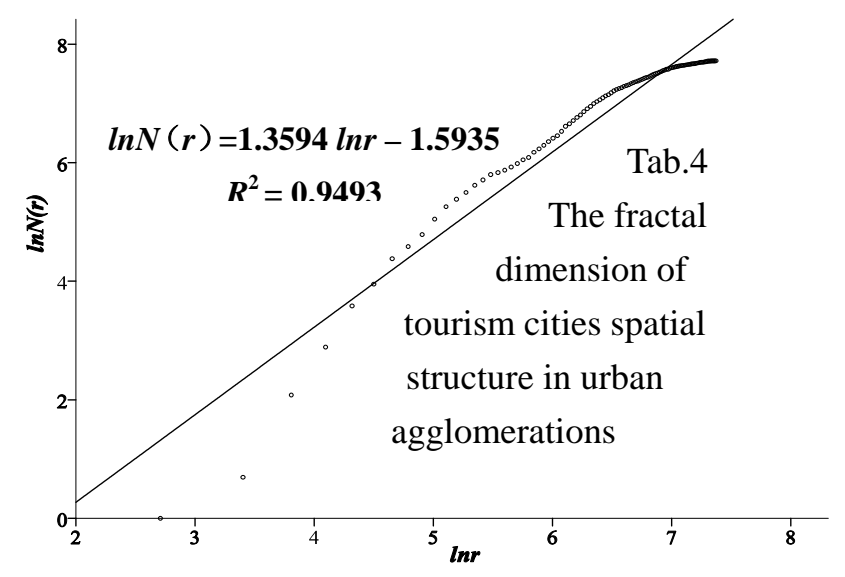

Fig.3 Double logarithmic plot of correlation dimension of cow distance

\begin{tabular}{|c|c|c|c|c|}
\hline $\begin{array}{c}\text { Urban } \\
\text { agglomeration }\end{array}$ & $\begin{array}{c}\text { Logarithmic regression } \\
\text { equation }\end{array}$ & $\begin{array}{l}\text { Fractal dimension } \\
\text { value }\end{array}$ & $\begin{array}{l}\text { Determination } \\
\text { coefficient }\left(R^{2}\right)\end{array}$ & $\begin{array}{l}\text { The ratio of cow } \\
\text { dimension to crow } \\
\text { dimension }(\rho)\end{array}$ \\
\hline \multirow{2}{*}{$\begin{array}{l}\text { Wuhan urban } \\
\text { agglomeration }\end{array}$} & $\ln N(r)=1.6521 \ln r-4.6982$ & $D=1.6521$ & 0.9821 & \multirow{2}{*}{0.8197} \\
\hline & $\ln N^{\prime}(r)=1.3542 \ln r-2.9006$ & $D^{\prime}=1.3542$ & 0.9666 & \\
\hline \multirow{2}{*}{$\begin{array}{l}\text { Changzhutan urban } \\
\text { agglomeration }\end{array}$} & $\ln N(r)=1.7515 \ln r-5.865$ & $D=1.7515$ & 0.9455 & \multirow{2}{*}{0.9218} \\
\hline & $\ln N^{\prime}(r)=1.6146 \ln r-4.9392$ & $D^{\prime}=1.6146$ & 0.9160 & \\
\hline \multirow{2}{*}{$\begin{array}{l}\text { Poyang Lake urban } \\
\text { agglomeration }\end{array}$} & $\ln N(r)=2.1136 \ln r-8.1819$ & $D=2.1136$ & 0.9397 & \multirow{2}{*}{0.7148} \\
\hline & $\ln N^{\prime}(r)=1.5108 \ln r-4.4318$ & $D^{\prime}=1.5108$ & 0.9594 & \\
\hline \multirow{2}{*}{$\begin{array}{l}\text { the city cluster along } \\
\text { Anhui-Yangtse River }\end{array}$} & $\ln N(r)=1.6129 \ln r-4.9248$ & $D=1.6129$ & 0.9567 & \multirow{2}{*}{0.8310} \\
\hline & $\ln N^{\prime}(r)=1.3403 \ln r-3.1881$ & $D^{\prime}=1.3403$ & 0.9339 & \\
\hline \multirow{2}{*}{$\begin{array}{l}\text { Central Henan urban } \\
\text { agglomeration }\end{array}$} & $\ln N(r)=1.9803 \ln r-6.2758$ & $D=1.9803$ & 0.9078 & \multirow{2}{*}{0.8678} \\
\hline & $\ln N^{\prime}(r)=1.7186 \ln r-5.2422$ & $D^{\prime}=1.7186$ & 0.9400 & \\
\hline \multirow{2}{*}{$\begin{array}{l}\text { Taiyuan urban } \\
\text { agglomeration }\end{array}$} & $\ln N(r)=1.4543 \ln r-4.5492$ & $D=1.4543$ & 0.9354 & \multirow{2}{*}{0.9559} \\
\hline & $\ln N^{\prime}(r)=1.3902 \ln r-4.7927$ & $D^{\prime}=1.3902$ & 0.9291 & \\
\hline \multirow{2}{*}{$\begin{array}{l}\text { urban agglomerations } \\
\text { of the central region }\end{array}$} & $\ln N(r)=1.4134 \ln r-2.2593$ & $D=1.4134$ & 0.9379 & \multirow{2}{*}{0.9618} \\
\hline & $\ln N^{\prime}(r)=1.3594 \ln r-1.5935$ & $D^{\prime}=1.3594$ & 0.9493 & \\
\hline
\end{tabular}


5. A comparative study on the spatial fractal comparison of the tourism cities of urban agglomerations in the central region

It is calculated of crow correlation dimension, cow correlation dimension and both dimension ratio for city system spatial structure in Wuhan urban agglomeration, Central Henan urban agglomeration, Changzhutan urban agglomeration, the city cluster along Anhui-Yangtse River, Poyang Lake urban agglomeration and Taiyuan urban agglomeration. The spatial structure of 6 urban agglomerations has the following characteristics:

5.1 The spatial structure has fractal characteristics, the whole spatial correlation dimension is higher than that of the individuals

There is obvious four non-scaling ranges of the spatial structure of the urban agglomerations in the central region, indicates that the spatial structure of the urban agglomerations in the central region has a fractal characteristic, and obvious multifractal characteristics with four subsystem.

The spatial correlation values of crow dimension of Wuhan urban agglomeration, Changzhutan urban agglomeration, Poyang Lake urban agglomeration, the city cluster along Anhui-Yangtse River, Central Henan urban agglomeration and Taiyuan urban agglomeration are respectively followed by 1.6521, 1.7515, 2.1136, 1.6129, 1.9803 and 1.4543. The spatial correlation values of crow dimension of other urban agglomerations except Poyang Lake urban agglomeration vary range from 1 to 2 . The above shows that the spatial distribution of the 6 urban agglomerations has fractal characteristics, and the fractal dimension is greater than 1 , and tends to be 2 . The spatial distribution of tourism cities of six urban agglomerations in the central region is relative uniform, the interaction between tourism cities is weak. From the value of crow spatial correlation fractal dimension of tourism city in six urban agglomerations, six urban agglomerations is sorted by the correlative intensity between tourism cities: Taiyuan urban agglomeration $>$ the city cluster along Anhui-Yangtse River $>$ Wuhan urban agglomeration $>$ ChangZhutan urban agglomeration > Central Henan urban agglomeration > Poyang Lake urban agglomeration.

The spatial crow correlation dimension for the whole urban agglomeration of the central region is 1.4134 , which shows that the interaction between the tourism cities in urban agglomeration of the central region is higher than that of any of urban agglomerations. On the whole, the tourism cities in six urban agglomerations concentrated in a geographical factor, namely spreading along the Beijing-Guangzhou Railway, the spatial structure self-organization of tourism cities has optimized trend in the urban agglomerations of the central region.

\subsection{The spatial structure has the characteristics of axis}

The spatial structure features of urban agglomeration is closely related to traffic factors, which is consistent with the traffic network spatial distribution of railway, highway, water transport, airline and so on. After calculation, the spatial correlation values of cow dimension of Wuhan urban agglomeration, Changzhutan urban agglomeration, Poyang Lake urban agglomeration, the city cluster along Anhui-Yangtse 
River, Central Henan urban agglomeration and Taiyuan urban agglomeration are respectively followed by 1.3542, 1.6146, 1.5108, 1.3403, 1.7186 and 1.3902. Which shows the spatial structure of the three urban agglomerations including Wuhan urban agglomeration, the city cluster along Anhui-Yangtse River and Taiyuan urban agglomeration presents the obvious axial distribution characteristics. The main tourism cities in Wuhan urban agglomeration spread along the Beijing-Guangzhou Railway and Shanghai-Chengdu Expressway, those in the city cluster along Anhui-Yangtse River spread along the Yangtze River waterway, and those in Taiyuan urban agglomeration spread along the Beijing-Kazakhstan, Beijing-Guangzhou channel axis.

5.3 The whole is superior to the individuals in the traffic network accessibility of tourism cities

After calculation, the ratio of cow dimension to crow dimension of Wuhan urban agglomeration, Changzhutan urban agglomeration, Poyang Lake urban agglomeration, the city cluster along Anhui-Yangtse River, Central Henan urban agglomeration and Taiyuan urban agglomeration are respectively followed by $0.8197,0.9218,0.7148$, $0.8310,0.8678$ and 0.9559 . The ratio of cow dimension to crow dimension of six urban agglomerations vary range from 0.5 to 1 .

The above shows that the traffic accessibility of tourism cities in six urban agglomerations is very good, and the traffic network between the tourism cities has a good foundation. At the same time the numerical size of the ratio of cow dimension to crow dimension reflects the difference of traffic network accessibility of tourism cities in six urban agglomerations, six urban agglomerations is sorted by the rank of traffic network accessibility between tourism cities: Taiyuan urban agglomeration > ChangZhutan urban agglomeration $>$ Central Henan urban agglomeration $>$ the city cluster along Anhui-Yangtse River $>$ Wuhan urban agglomeration $>$ Poyang Lake urban agglomeration. The ratio of cow dimension to crow dimension for the whole urban agglomeration of the central region is 0.9493 , which shows that the the traffic network between tourism cities in the whole urban agglomeration of the central region is higher than that of any of urban agglomerations.

\section{Acknowledgment}

This work was financially supported by Humanities and social Scientific Research Guidance Project for Hubei Provincial Department of Education (16G149) fund.

Corresponding author: LIU Chun, Wuhan Technology and Business University, Department of Management, Wuhan 430065, CHINA

\section{References:}

[1] YAO Shi-mou, ZHU Ying-ming, et al. Chinese urban agglomeration (Second Edition) [M]. Hefei: University of Science and Technology of China press, 2001: 53-90.

[2] BIAN Xian-hong. Research on Urban Tourism Spatial Structure[J]. Geography and Geo-Information Science, 2003, 19(1): 105-108.

[3] Gunn C A,Turgut Var. Tourism Planning: Basics Concepts Cases[M]. New York: Rutledge, 2002.

[4] Leiper N. Tourism Management [M].Collingwood, VIC: TAFE Publications, 1995. 
[5] Douglas G Pearce. Tourism in Paris Studies at the Microscale [J]. Annals of Tourism Research, 1999, 26(1): 77-97.

[6] WENG Jin, YANG Kai-zhong. Spatial structure of tourism system: spatial model for monopolistic competition with asymmetry [J]. Systems Engineering-Theory \& Practice, 2007, 27(2): 76-82.

[7] Marrocu Emanuela,Paci Raffaele. They arrive with new information. Tourism flows and production efficiency in the European regions [J]. Tourism Management, 2011, 32(4): 750-758.

[8] LIN Lan, YANG Lei-lei, DAI Xue-jun, et al. A Fractal Study on the Spatial Structure of Tourism Destination System in Fujian Province[J]. Journal of Fujian Normal University (Natural Science Edition), 2011, 27(6): 95-100.

[9] JIANG Ming-ping, ZHOU Nian-xing, LIANG Yan-yan. The Difference of Regional Tourism Spatial Structure in Jiangsu Province Based on Aggregation and Fractal[J]. Resources and Environment in the Yangtze Basin, 2012, 21(Z2): 81-88.

[10] LIU Da-jun, XIE Shuang-yu, LU Fu-rong, et al. A Fractal Study on The Spatial Structure of Excellent Tourism Cities in Sichuan Province[J]. Resources and Environment in the Yangtze Basin, 2013, 22(3): 285-290.

[11] DUAN Bing. A Study on the Scale and Spatial Structure of Tourism Center in Yangtze River Delta Based on Fractal Theory[J]. Journal of Henan University (Natural Science), 2015, 45(2): 181-186.

[12] ChHEN Hao, LU Lin, ZHANG Jin-he, et al. Analysis of Spatial Tourist Structure and Optimizing for the Zhujiang River Delta Urban Cluster[J]. Scientia Geographica Sinica, 2008, 28(1):131-136.

[13] WANG Lang, ZHANG He-qing. Analysis of spatial tourism structure and optimizing approaches for the Guanzhong-Tianshui economic region cities[J]. Journal of Northwest University (Natural Science Edition), 2010, 40(5): 891-895.

[14] ZHANG Hong, XIA Ming. Research on Tourism Spatial Structure of Anhui Province-—Based on Tourism Centrality Degrees and Tourism Economic Contact[J]. Economic Geography, 2011, 31(12):2116-2121.

[15] CHEN Hao, LU Lin, ZHENG Shan-ting. The Tourism Spatial Pattern Evolution of the Pearl River Delta[J]. Acta Geographica Sinica, 2011, 66(10): 1427-1437.

[16] SHEN Jing-hong, LU Yu-qi, ZHOU Yu-cui, et al. Spatial Linkage Pattern of Tourism Economy in the Wanjiang Urban Agglomeration[J]. Resources and Environment in the Yangtze Basin, 2012, 21(12): 1434-1441.

[17] CAO Fang-dong, HUANG Zhen-fang, WU Li-min, et al. City Tourism Economic Contact Measurement and Spatial Integration Based on the Temporal Distance -A Case Study of the Yangtze River Delta[J]. Economic Geography, 2012, 32(12): 157-162.

[18] SUN Dong-qi, ZHANG Jing-xiang, HU Yi, et al. The Formation of Metropolitan Shadow From the Perspective of Industry Spatial Contacts: A Comparison Between Changjiang River Delta and Beijing-Tianjin-Hebei Metropolitan Region[J]. Scientia Geographica Sinica, 2013, 33(9): 1043-1050.

[19] FANG Ye-lin, HUANG Zhen-fang, TU Wei. Spatial Differences of Tourism Economy in Yangtze River Delta from the Perspective of Social Network[J]. Tropical Geography, 2013, 33(2): 212-218.

[20] YU Hu, CHEN Tian, LU Lin, et al. Structure of tourist economy network and its spatial development pattern in Jianghuai Urban Agglomeration[J]. Progress in Geography, 2014, 33(2): 169-180.

[21] LIU Chun. Study on the Spatial Structure of Tourism Economy in Middle Area of China Based on Social Network Analysis[J].World Regional Studies, 2015, 24(2): 167-176

[22] BIAN Xian-bong, ZHANG Jia-qing. Theory of Node-axes Evolving and Diffusing and Regional 
Tourist Spatial Structure in the Yangtze River Delta[J]. Journal of Southern Yangtze University ( Humanities\&Social Sciences), 2007, 6(2): 59-65.

[23] XIE Shou-hong, HE Jia-feng. Study on Spatial Disparity of Tourism Economic Development in Yangtze River Delta[J]. East China Economic Management, 2008, 22(10): 4-8.

[24] LI Hong-bo, ZHANG Xiao-lin, LI Yue-zheng. Study on the Tourism Spatial Structure of Liaoning Coastal Economic Zone Based on Pole-Axis Theory[J]. Economic Geography, 2011, 31(1): 156-161.

[25] ZHAO Rui-xia, HU li-ming, LIU You-jin. Study on spatial pattern of Urban Agglomeration Based on Logistic model[J].Statistics and Decision, 2011(3): 55-57.

[26] ZHU Fu-biao, LU Lin, YU Ran, et al. Tourism Spatial Structure Evolution of Metropolitan Area: A Case Study of Changjiang River Delta Metropolitan Area[J]. Scientia Geographica Sinica, 2012, 32(5): 570-576.

[27] Fang Fa-lin. A Study On The Spatial Difference of Urban Agglomeration Based on Tourism Foreign Exchange Income: A Case Study of Nanjing Metropolitan Area[J]. Research on Development, 2013(6): 102-106.

[28] CHEN Yanguang, LIU Jisheng. Studies on the Fractals of Town-Size Distribution of Urban System in the North Henan Province[J]. Human Geography, 1998, 13(1): 22-29.

[29] LIU Ji-sheng, CHEN Yan-guang. Fractal Dimensions of Hierarchical Structure of Urban Systems And The Methods of Their Determination[J].Geographical Research, 1998, 17(1): 82-89. 